\title{
Innovations and Revolutions in Reducing Retinal Ganglion Cell Loss in Glaucoma
}

\author{
Mary Kelada , Daniel Hill , Timothy E. Yap , Haider Manzar \& M. Francesca \\ Cordeiro
}

To cite this article: Mary Kelada, Daniel Hill , Timothy E. Yap , Haider Manzar \& M. Francesca Cordeiro (2020): Innovations and Revolutions in Reducing Retinal Ganglion Cell Loss in Glaucoma, Expert Review of Ophthalmology, DOI: 10.1080/17469899.2021.1835470

To link to this article: https://doi.org/10.1080/17469899.2021.1835470 Accepted author version posted online: 12
Oct 2020.

Submit your article to this journal ¿त

Q View related articles $\sqsubset$

View Crossmark data $\asymp$ 
Publisher: Taylor \& Francis \& Informa UK Limited, trading as Taylor \& Francis Group

Journal: Expert Review of Ophthalmology

DOI: $10.1080 / 17469899.2021 .1835470$

\section{Innovations and Revolutions in Reducing Retinal Ganglion Cell Loss in Glaucoma}

$\underline{\text { Mary Kelada }^{2} \text {, Daniel Hill }}{ }^{3}$, Timothy E. Yap ${ }^{1,2}$, Haider Manzar ${ }^{2}$, M. Francesca Cordeiro ${ }^{1,2,3, *}$

1 The Western Eye Hospital, Imperial College Healthcare NHS Trust (ICHNT), London NW1 5QH, UK

2 The Imperial College Ophthalmic Research Group (ICORG), Imperial College London NW1 5QH, UK

3 Glaucoma and Retinal Neurodegeneration Group, UCL Institute of Ophthalmology, London EC1V 9EL, UK

* Correspondence: Prof M. F. Cordeiro, UCL Institute of Ophthalmology 11-43 Bath Street, London EC1V 9EL UK E-mail: M.Cordeiro@ucl.ac.uk

\section{Abstract:}

Introduction: Glaucoma remains the leading cause of irreversible blindness. Although the loss of retinal ganglion cells (RGCs) is an established hallmark of glaucoma, reduction of intraocular pressure (IOP) is a widely used evidence-based management approach, even in normotensive patients. However, despite optimal pressure control, some patients progress to lose vision. Areas covered: This review provides a summary of latest methods aimed at reducing RGC loss with the objective of preserving vision, categorised by mechanism of action. We discuss both the newest ways in which IOP can be reduced, alongside 'pressureindependent' pharmacological therapies and developments in bioengineering. The conducted PubMed search included the terms: "glaucoma pathophysiology", "IOP-lowering agents", "retinal ganglion cell apoptosis", "neuroprotection", "stem cells", "imaging". 
Expert opinion: With many agents failing to successfully translate into clinical use, further understanding of the underlying disease process is required, along with novel biomarkers that will enable timely and reliable quantification of treatment effect.

Keywords: apoptosis; excitotoxicity; glaucoma; neuroprotection; neurotrophic factors; stem cells

\section{Innovations and Revolutions in Reducing Retinal Ganglion Cell Loss in Glaucoma}

Mary Kelada ${ }^{2}$, Daniel Hill ${ }^{3}$, Timothy E. Yap ${ }^{1,2}$, Haider Manzar ${ }^{2}$, M. Francesca Cordeiro ${ }^{1,2,3, *}$

1 The Western Eye Hospital, Imperial College Healthcare NHS Trust (ICHNT), London NW1 $5 \mathrm{QH}, \mathrm{UK}$

2 The Imperial College Ophthalmic Research Group (ICORG), Imperial College London NW1 5QH, UK

${ }^{3}$ Glaucoma and Retinal Neurodegeneration Group, UCL Institute of Ophthalmology, London EC1V 9EL, UK

Corresponding Author*: Francesca Cordeiro

Email: M.Cordeiro@ucl.ac.uk 


\section{$\underline{\text { Abstract: }}$}

Introduction: Glaucoma remains the leading cause of irreversible blindness. Although the loss of retinal ganglion cells (RGCs) is an established hallmark of glaucoma, reduction of intraocular pressure (IOP) is a widely used evidence-based management approach, even in normotensive patients. However, despite optimal pressure control, some patients progress to lose vision. Areas covered: This review provides a summary of latest methods aimed at reducing RGC loss with the objective of preserving vision, categorised by mechanism of action. We discuss both the newest ways in which IOP can be reduced, alongside 'pressureindependent' pharmacological therapies and developments in bioengineering. The conducted PubMed search included the terms: "glaucoma pathophysiology", "IOP-lowering agents", “retinal ganglion cell apoptosis", "neuroprotection”, "stem cells", "imaging”. Expert opinion: With many agents failing to successfully translate into clinical use, further understanding of the underlying disease process is required, along with novel biomarkers that will enable timely and reliable quantification of treatment effect.

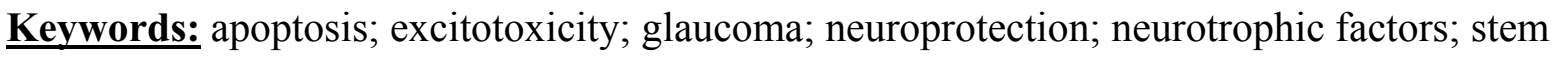
cells 


\section{Article Highlights:}

- The pathophysiology of glaucoma comprises a network of interacting pathways that must be carefully considered when identifying novel therapeutic targets and developing treatments.

- Excitotoxic RGC stimulation could potentially increase nuclear translocation of histone deacetylases, repressing the transcription of certain genes, as seen in the early stages of RGC apoptosis. Further study of this pathway is required for the identification of efficacious therapeutic targets.

- Retinal bioenergetic research is gaining increasing interest in glaucoma, with monocarboxylate transporter- 2 and insulin signalling having recently been identified as potential therapeutic targets.

- Cell and genetic therapies could provide a stable source of neurotrophic factors, with clinical trials currently underway.

- The mechanisms of action of some traditional IOP-lowering therapies (such as alpha2 agonists, prostaglandin analogues and carbonic anhydrase inhibitors) are being reassessed to evaluate their potential as dual-action agents with both IOP-lowering and neuroprotective properties.

- Advances in knowledge of metabolomics, genetics and imaging could provide future biomarkers for research and enable accurate risk stratification of patients, allowing for more personalised and targeted therapy. 


\section{1) Introduction: Is Neuroprotection Everything?}

The glaucoma 'spectrum' has one main hallmark: the loss of retinal ganglion cells (RGC). This is evident in the reduction of associated nerve fibres with eventual excavation of the optic nerve head [1,2] and development of characteristic visual field deficits[1]. Reducing this process or the impact of it, is therefore the ultimate aim of all treatment strategies in glaucoma. However, the mechanistic routes leading to an apparent final common pathway may be numerous, with overlapping molecular interactions, phenotypes and risk factors. It follows that the development of targeted, personalised therapies for the 11 million predicted to suffer bilateral blindness by 2020 [3] is a complex challenge that requires a novel approach.

One of the pertinent challenges facing the glaucoma community is the continued loss of vision that can occur despite optimal control of intraocular pressure (IOP) [4]. Although lowering IOP is supported by a firm evidence base [5], there are believed to be a number of additional mechanisms that contribute to glaucomatous pathophysiology which could also provide therapeutic targets [6-8]. In the past few decades the term "neuroprotection" has been used to describe a subset of treatment modalities in this category, which "aim to prevent, hinder and in some cases, reverse neuronal cell damage" [2]. If the pathogenesis of glaucoma is as complex as we now believe it to be, the network of interacting pathways must be carefully considered when developing treatments. Whilst a novel treatment may be aimed at an individual pathway, the consequences of this action should be considered with the likely homeostatic reactions that will follow. It is conceivable that the failure to translate 'neuroprotective' therapies to clinical practice is a lack of 'joined-up thinking' in this regard. Here, we aim to summarise the part of the 'network' of glaucomatous processes characterised 
thus far and the recent ways in which these have been targeted (as summarised in Figure 1). It is hoped that this approach will bring us closer to developing more efficacious treatments in the future.

\section{2) Targeting excitotoxicity}

Excitotoxicity refers to receptor overstimulation by excitatory neurotransmitters, and is thought to play a pathogenic role in glaucoma as well as other neurodegenerative conditions including Alzheimer's disease $[9,10]$. It has been demonstrated that excitotoxicity in relation to glutamate has a deleterious effect on the health of RGC populations through in-vitro and in-vivo studies [11,12]. Glutamate excitotoxicity is thought to be mediated mainly through $\mathrm{N}$ methyl-D-aspartate (NMDA) receptors [13], although other glutamate receptors exist. A cascade of nitric oxide-mediated intracellular events are then believed to lead to intracellular calcium release and RGC death $[9,14,15]$. Cell death is thought to predominantly occur via caspase-dependent apoptosis [16] with other modes of cell death including a controlled formed of necrosis ('necroptosis') and neuroinflammation also thought to be implicated $[17,18]$. Controversy over the role of excitotoxicity and the paucity of evidence for raised glutamate levels in the vitreous may be clarified when considering the circumstances by which the NMDA receptor is hyper-activated, not necessarily requiring raised levels of glutamate [19].

NMDA receptor modulation has accordingly been explored for its neuroprotective potential in glaucoma. Memantine (Table 1) is a non-competitive NMDA receptor antagonist [20] taken to clinical trial following several preclinical studies that demonstrated its potential in glaucoma therapy [21-23]. Unfortunately, two large, double-blinded, randomised controlled 
trials (RCTs) did not discover any neuroprotective effect of a 48 month course of daily oral memantine [24]. However, the disappointing results of this trial could, at least in part, be due to limitations in trial design. For example, given that the treatment regimens were left to the discretion of the investigator, there may have been significant variation in treatment between groups. Treatment variation may also have arisen from patient misclassification as low tension glaucoma cases as there was no set IOP cut-off defined in the protocol. Alternatively, the lack of clinical edivence may be an argument for the poor suitability of this pathway as a target in retinal neuroprotective therapies, as shown in some pre-clinical studies [25].

It has recently been proposed that increasing the concentration of memantine delivered to intra-ocular tissues by using novel formulations such as nanoparticles could yield more promising results than that of the aforementioned RCTs, with rodent models demonstrating beneficial results in glaucoma and ocular hypertension (OHT) [26]. Memantine-loaded nanoparticles, however, have not yet been investigated in humans.

Brimonidine (Table 1) is an $\alpha 2$ adrenergic receptor agonist believed to have inhibitory effects on NMDA receptors as well as non-IOP dependent neuroprotective benefits [27,28]. The Low-Pressure Glaucoma Treatment Study (LoGTS) compared the efficacy of brimonidine to timolol, a non-selective beta-adrenergic antagonist [29]. Of the timolol group, $39.2 \%$ of patients had visual field progression after 2 years compared to only $9.1 \%$ of the brimonidine group, with comparable IOP reduction in both groups. Therefore, it was concluded that brimonidine reduced the progression of visual field loss more so than timolol. Although these results were seen to replicate those seen in animal studies [27,28], it is important to note the higher dropout rate in the brimonidine group due to side effects of the drug $(28.3 \%$ vs $11.4 \%$ of timolol), which may have skewed the results $[29,30]$. There is still, 
therefore, some way to go before the neuroprotective effects of brimonidine are proven and translated to clinical practice.

Curcumin (Table 1) is a polyphenol found in turmeric (Curcuma longa), historically been believed to possess beneficial health effects in traditional medicine practices. Curcumin has been demonstrated to protect rodent retinal neurons against NMDA-induced excitotoxicity [31] and has thus gained interest in medical research as a commonly used and naturally occurring foodstuff. It has also been shown to possess antioxidative and anti-inflammatory properties and act against mitochondrial dysfunction [31-33]. Curcumin has also been shown to activate calmodulin-dependent protein kinase II (CamKII) and reduce serine/threonine phosphatase's enzymatic activity to increase GluN2A NMDA receptor subunit expression, conferring neuroprotective effects [34]. However, the challenge with curcumin is its poor oral bioavailability [35]. It has been proposed that local administration of curcumin-loaded nanoparticles offers greater bioavailability than systemic delivery and provides a hydrophobic environment for this drug of limited water solubility. Curcumin-loaded nanoparticles have recently been shown to confer neuroprotection against glutamate-induced excitotoxicity in retinal cultures in vitro [36]. They also significantly preserved RCG density in both OHT and partial optic nerve resection rodent models compared to control [36]. Further refinement and clinical trials are awaited in order to evaluate its potential for clinical use.

More recently, the role of histone deacetylases (HDACs) has been investigated. HDACs act to reverse the acetylation of lysine, which restores its positive charge and stabilises the structure of chromatin [37]. This altered chromatin structure leads to the repression of the transcription of certain genes, such as Thyl and Nrn1, as seen in the early stages of RGC 
apoptosis [37]. The role of HDACs in glaucoma pathophysiology first gained interest a decade ago, when increased nuclear-cytoplasmic shuttling of HDAC3 in murine RGCs was noted after optic nerve crush (ONC), compared to control [38]. Within the same study, inhibition of HDACs using trichostatin A lead to significantly less RGC loss, as monitored by total cell counts in the ganglion cell layer, in ONC mice compared to controls. These findings suggest that histone deacetylation plays a key role in the apoptotic pathway, although the exact mechanistic pathway in glaucoma remained unclear.

A recent pre-clinical trial demonstrated in-vivo excitotoxic stimulation of murine RGCs using intravitreal NMDA injections to increase nuclear HDAC3, as well as HDAC4 and 5, compared to controls [39]. Although separate and combined intravitreal injections of an HDAC1/3-specific inhibitor (etinostat) and HDAC4/5-specific inhibitor (LMK-235) were not found to provide immediate protection against NMDA toxicity, they did prevent further degeneration of RGCs over time. The findings of this study suggest in-vivo excitotoxicity could increase nuclear levels of HDACs. Perhaps further study of this pathway could yield novel targets in glaucoma therapy.

\section{3) Targeting mitochondrial and metabolic dysfunction}

Mitochondria produce the majority of energy required for axonal function. Oxidative phosphorylation by the electron transport chain in their inner membranes produces the energy currency adenosine tri-phosphate (ATP) [40]. Reactive oxidative species (ROS) are produced as a by-product of this process. These molecules can be highly damaging to lipids, carbohydrates, proteins and nucleic acids, and hence, are kept within a tight physiological range by antioxidant mechanisms. Such mechanisms are overwhelmed when there is 
mitochondrial dysfunction, leading to oxidative stress and resultant mutations to mitochondrial DNA [41,42]. Ultimately, this results in age-related ocular pathologies, such as glaucoma [43].

Coenzyme-Q10 (CoQ10) (Table 1) is a mitochondrial-targeting antioxidant, with research suggesting it has a potential role in the management of glaucoma. CoQ10 has been found to promote anti-inflammatory gene expression and reduce oxidative stress through lowering concentrations of extracellular glutamate $[44,45]$. This in turn, does not disrupt the mitochondrial environment and produces less ROS [46]. Again, poor solubility is a barrier to good bioavailability as in the case of curcumin. There is ongoing research to study the most effective route of administration for CoQ10. Murine studies have shown oral CoQ10 to be beneficial in axonal and RGC protection [47]. Recently, combined topical administration of CoQ10 with an inhibitor of P-glycoprotein responsible for multi-drug efflux (D- $\alpha$-Tocopherol polyethylene glycol 1000 succinate, TPGS) was evaluated in-vivo in unilateral OHT rodent glaucoma models [48]. DARC (Detection of Apoptotic Retinal Cells) imaging following twice-daily administration of CoQ10/TPGS for three weeks demonstrated the number of apoptotic cells in treated eyes to be significantly reduced compared to untreated control OHT eyes, showing a substantial neuroprotective effect [48].

There have also been clinical trials of CoQ10. Topical administration of a preservative-free solution containing CoQ10 and vitamin E d- $\alpha$ tocopheryl polyethylene glycol 1000 succinate (Vitamin E TPGS), in combination with $\beta$-blocker therapy in open-angle glaucoma patients showed better inner retinal function than those on $\beta$-blocker monotherapy [49]. Another study has shown CoQ10 to reduce aqueous superoxide dismutase levels (marker of oxidative stress) in combination with prostaglandin analogue (PGA) in comparison to the PGA only 
group [50]. Currently, a double-masked, randomised, controlled trial is underway to evaluate the efficacy of CoQ10 and vitamin E combined with PGA therapy, assessing the time to development of visual field defects between groups (NCT03611530) [51].

Citicoline (Table 1) is an endogenous mononucleotide involved in the synthesis of membrane phospholipids [52]. The use of citicoline as a neuroprotective agent has been explored in amblyopia, stroke, Alzheimer's and Parkinson's disease [53-56]. Citicoline in its original form, cytidine 5'-diphosphocholine, is unable to cross the blood-brain barrier (BBB), however, once hydrolysed in the liver into cytidine and choline, the components are able to cross the BBB and then reform back into citicoline [57]. Amongst its neuroprotective actions, citicoline is able to maintain cardiolipin and sphingomyelin concentrations in mitochondria, thereby restoring phosphatidylcholine levels.

Citicoline may also be of relevance in the treatment of glaucoma by the reduction of apoptosis and promotion of axonal regeneration. Citicoline has been shown to permit significantly less TdT-dUTP terminal nick-end labelling (TUNEL)- labelled apoptotic cells compared to controls in mouse retinal culture[58]. Other work has found citicoline to be associated with increased expression of the anti-apoptotic protein Bcl-2 in a rat partial optic nerve crush model [59].

A randomised prospective controlled clinical study of 56 patients using pattern electroretinogram (PERG) and visual evoked potentials (VEPs) as outcomes showed improved retinal characteristics in those applying topical citicoline three times a day for 4 months in addition to beta-blocker, when compared to their initial baseline and beta-blocker only controls. Furthermore, those with greater electrophysiological dysfunction at baseline 
showed greater improvement [60] Systemic treatment via pulsed intramuscular injection has also been examined, including one study with a treatment period extended up to 8 years, reporting the stabilisation or improvement of glaucomatous visual dysfunction on treatment [61]. The results of a double-masked, placebo-controlled trial of citicoline eyedrops observing visual field and structural OCT parameters are awaited (NCT04020705).

The field of retinal bioenergetic research has gained increasing interest in glaucoma, with energy insufficiency at the optic nerve head having been suggested to play a role in the pathogenesis of glaucoma [62]. Recently, the expansion of energy input mechanisms of retinal cells has been described as a potential neuroprotective method. Monocarboxylate transporters (MCTs) act to transport lactate, pyruvate and ketones across cell membranes. Harun-Or-Rashid et al [63] demonstrated that the reduction of murine retinal levels of MCT2 using AAV2-cre lead to a significant reduction in visual evoked potential and ATP production. The same research group also demonstrated that virally-induced overexpression of MCT2 in DBA/2J (D2) glaucoma models, as well as murine magnetic bead models of OHT, increased RGC density and axon numbers compared to untreated mice [63]. MCT2 overexpression was also demonstrated to increase mitochondrial function (represented by succinate dehydrogenase activity) in both glaucoma models, compared to untreated control mice [63]. The findings of this preclinical study offer promising insight into the potential use of metabolic interventions as neuroprotective mechanisms.

Insulin signalling has also recently gained attention for its potential as a neuroregenerative therapeutic target. Both topical and intra-peritoneal administration of human recombinant insulin have been demonstrated to mediate mTORC1/2-dependent survival in axotomised murine glaucoma models [64]. Insulin-treated mice demonstrated $60 \%$ RGC survival two 
weeks after axonal injury, compared to just 10\% survival in vehicle-treated mice [64].

However, the treatment effect was transient, with a gradual decrease in RGC survival to $25 \%$ and $8 \%$ in insulin and vehicle treated mice, respectively. These pre-clinical findings suggest that insulin could play a transient role in the regeneration of RGCs and raise the question of whether long-term topical administration of insulin could result in more long-lasting effects. At the time of writing, a phase I clinical trial investigating the safety of topical insulin is about to commence patient recruitment (NCT04118920).

\section{4) Targeting neurotrophic factor deficits}

Neurotrophic factors (neurotrophins) are endogenously secreted proteins that act to maintain neuronal cellular homeostasis and promote cell survival $[12,65,66]$. As a family, these peptides have been examined in the context of multiple neurodegenerative diseases for natural therapeutic exploitation [67-69]. Brain-derived neurotrophic factor (BDNF) is a highly studied trophic factor expressed by RGCs, a lack of which is thought to contribute to the pathogenesis of glaucoma $[7,70]$. Anterograde transport carries BDNF along the optic nerve to second-order neurons in the lateral geniculate nucleus and superior colliculus of the brain [7]. Live-imaging studies have shown a fall in BDNF transport before RGC death, proposing this as a contributing factor to the pathogenesis of glaucoma $[71,72]$.

Drug delivery challenges have not eluded the study of neurotrophins. A number of animal studies modelling optic nerve injury have investigated intravitreal injections of BDNF as a neuroprotective agent $[73,74]$, whilst it has also been reported that BDNF requires the coadministration of the free radical scavenger N-tert-butyl-(2-sulfophenyal)-nitrone (Table 1) [75]. High levels of BDNF are required to produce short-lived neuroprotective effects [75- 
77]. This could be attributed to downregulation of receptors, short-lived binding and activation, or the blood-retina barrier's poor permeability to BDNF. As a result, research focus has moved on to agonists of the tropomyosin related kinase receptor B (TrkB)[78,79]. $\mathrm{BDNF} /$ TrkB signaling has been shown to confer neurotrophic support via three pathways the phosphatidylinositol (PI3K), mitogen-activated protein kinase (MAPK) and phospholipase C$\gamma(\mathrm{PLC} \gamma)$ signaling pathways [80].

Forskolin is a naturally occurring product obtained from the roots of the Plectranthans barbans plant [81], thought to increase the translocation of TrkB from intracellular stores to the membrane of retinal ganglion cells. Forskolin acts by activating adenylate cyclase in a receptor-independent fashion, increasing intracellular cyclic adenosine monophosphate (cAMP) production which in turn, increases TrkB insertion into the cell membrane [82]. Forskolin has also been demonstrated to increase BDNF production in astrocytes and endothelial cells [83]. Moreover, foskolin has been shown to decrease IOP by increasing the outflow of aqueous humour through the trabecular meshwork, whilst simultaneously decreasing its production at the ciliary epithelium [84]. Forskolin advocated by some as a supplement for glaucoma patients given its purported IOP-lowering effects; oral administration has been demonstrated to reduce IOP and increase pattern electroretinography (PERG) amplitude in treated patients compared to control [85].

7,8-Dihydroxyflavone (7,8 DHF) (Table 1) is an orally bioactive TrkB agonist that is able to cross the blood-brain barrier to exert neuroprotective effects on the central nervous system (CNS) [86]. It is also postulated to prevent oxidative and excitotoxic-induced apoptosis of RGCs and retinal neural cell precursors in rat models though upregulating downstream AKT and MAPK/ERK survival signaling [87]. Other studies using agonists of TrkB receptors have 
shown them to preserve the ganglion cell complex on OCT imaging in animal models of glaucoma $[77,88]$. In contrast to other neurodegenerative conditions such as amyotrophic lateral sclerosis [89] and Parkinson's disease [90], no clinical trials have been conducted using direct application of BDNF or TrkB receptor agonists in glaucoma.

Another neurotrophic factor of interest is ciliary neurotrophic factor (CNTF) (Table 1). Virally-mediated increased CNTF expression has been demonstrated to confer significant neuroprotective effects, protecting 15\% more RGCs than virally-mediated increased BDNF expression in rodent models of glaucoma [91]. A major obstacle in the use of CNTF, however, is the fact that systemic application does not reach the CNS effectively. CNTF therefore requires local administration [92], this will be explored in further detail in "Novel cellular therapies to reduce RGC loss".

Recent pre-clinical models have demonstrated that glial cell line-derived neurotrophic factor (GDNF) could act synergistically with CNTF to confer increased neuroprotection to RGCs than either factor alone [93]. The intravitreal transplantation of GDNF-expressing neuronal stem (NS) cell lines one day after RGC axotomy in murine models increased the survival of RGCs by 3.8 times, compared to control retinas. Similarly, the intravitreal transplantation of CNTF-expressing NS one day after axotomy of RGCs in adult mice resulted in 3.7-fold more RGCs than in control retinas. However, when GDNF and CNTF expressing NS were coadministered, RGC survival was dramatically increased, with 14.3-fold more RGCs than control retinas 8 weeks after injury compared to control retinas [93]. Although yet to progress to clinical trials, the combination of neurotrophic factors could represent a novel neuroprotective strategy in glaucoma. However, this strategy may also be limited by issues of bioavailability. 


\section{5) Novel cellular therapies to reduce RGC loss}

Cell therapies have gained significant interest owing to their promise in the management of diseases such as multiple sclerosis and Parkinson's, amongst others [94,95], and their lack of dependence on patient compliance with treatment. To overcome the problems described above with the direct administration of neurotrophins, cell and genetic therapies have been sought to provide a more stable source of neurotrophic factors. NT-501 is an investigative implantable device releasing CNTF. This 'encapsulated cell therapy' (ECT) uses modified RPE cells (ARPE-19) secreting CNTF contained within a semi-permeable polyethersulfone membrane (Renexus ${ }^{\circledR}$, Neurotech Pharmaceuticals) that is inserted into the posterior chamber. A retrospective study of patients recruited for the initial phase I trials of this device demonstrated its safety, with no systemic CNTF or CNTF antibodies detected up to 2 years after the trial [96]. Results phase II randomized, sham-controlled, masked trials in glaucoma (NCT02862938) and macular telangiectasia type 2 (NCT03071965) are awaited.

With regards to BDNF, adeno-associated virus (AAV) intravitreal gene therapy has been shown to increase BDNF production and TrkB receptor expression long-term, in the inner retina of optic nerve crush mouse models, as well as laser-induced ocular hypertension rat models [97]. This finding was coupled with the observation of sustained elevation of downstream ERK and AKT signalling over 6 months, along with the prevention of receptor downregulation in second-generation constructs [97]. However, this has not yet progressed to clinical trials.

\section{6) Targeting of raised intraocular pressure continues and evolves}


Controlling intraocular pressure by regulating aqueous production and outflow in the anterior segment of the eye still remains the most evidence-based method of reducing loss of retinal ganglion cells in glaucoma. Raised IOP is thought to compress RGC axons running into the posterior structures of the eye, in particular the lamina cribrosa, at the point where RGC axons form the optic nerve[98,99]. Additionally, axonal transport of neurotrophic factors is thought to be disrupted for similar reasons [100]. Thus, continued innovation in novel therapies and routes of administration to overcome issues with medication compliance and continuous drug delivery are important.

Traditionally, IOP-lowering agents have been subcategorised into increasing aqueous outflow or reducing its production. This has been further sophisticated by novel nitric oxide (NO) donor compounds as well as nanoparticulate systems that target therapy specifically to the ciliary muscles and trabecular meshwork. The mechanisms of action of established IOPlowering therapies are also being re-assessed to evaluate their potential as dual-action agents with both IOP-lowering and neuroprotective properties.

Nitric Oxide (NO) is a gaseous compound and signalling molecule that can reduce IOP by relaxing the trabecular meshwork and increasing aqueous humour outflow [101,102], in addition to its neuroprotective function in the CNS at physiological levels [103]. NO-donor compounds, such as S-nitrosthiols, metal nitrosyls and organic nitrites, amongst others, have been shown to release NO and lower IOP [104,105]. Sodium nitroprusside (SNP), a metal nitrosol, has been demonstrated to be a particularly efficacious at relaxing trabecular meshwork in vitro [106]. More recently, Hu et al[107] demonstrated SNP- loaded mesoporous silica nanoparticles to be superior to conventional SNP solution in terms of both magnitude and duration of IOP reduction in an in vivo murine glaucoma model. The SNP- 
loaded nanoparticles were noted to increase the duration of IOP reduction from 3 hours to 48 hours compared to SNP solution [107]. This study highlights the potential use of nanotechnology in the delivery of NO-donors; however, the findings remain to be explored in clinical trials.

The FDA have recently approved latanoprostene bunod [108]. This medication is cleaved into latanoprost acid and butanediol mononitrate (a NO-donating moiety) in the presence of ocular esterases. It has been demonstrated to be a more efficacious than traditional latanoprost at reducing diurnal IOP [108]. Beyond this, latanoprostene bunod has been demonstrated to significantly increase diurnal perfusion pressure compared to baseline [109]. It will be interesting to explore whether this confers additional neuroprotective properties to this medication.

Prostaglandin analogues (PGAs) are thought to possess a superior IOP-lowering profile compared to other classes of glaucoma therapeutic agents such as ß-blockers and carbonic anhydrase inhibitors [110]. This is thought to be accomplished via increased 'uveoscleral outflow'. However, more recently, PGAs have been proposed to confer anti-apoptotic effects as seen in rodent RGCs both in vitro and in vivo [111,112]. Several mechanisms, including COX-2 and caspase-3 inhibition have been proposed to mediate the neuroprotective effects of PGAs $[113,114]$, however, the exact mechanism has not yet been conclusively established.

Beta-adrenergic receptor blockers (ß-blockers) are the original class of glaucoma agents[115], and exert their effect by reducing aqueous humour secretion from the ciliary body. However, timolol has poor ocular bioavailability, owing to its hydrophobic nature which slows trans-corneal diffusion [116]. It can also be absorbed into the systemic 
circulation through the nasolacrimal duct, leading to respiratory and cardiovascular systemic side-effects [117].

Nanotechnology has the potential to optimise this treatment strategy through increasing the ocular bioavailability of timolol and minimising its systemic absorption. Shokry et al [118] recently demonstrated gelatin nanoparticles to be safe and efficacious in timolol-delivery methods during their in vivo study on rabbits. It is worth noting however, that mild-moderate oedema was observed in the corneal stroma of treated rabbits during the first two weeks.

Genetic editing could also contribute to the lowering of IOP. Recently, single intravitreal injection of an adeno-associated viral vector of CRISPR-Cas9 has been demonstrated to successfully disrupt Aquarporin-1 transmembrane channels in the ciliary bodies of mice invivo [119]. This lead to a mean reduction of baseline IOP by $22 \%(2.9 \mathrm{mmHg})$ relative to the contralateral control eye in mice with healthy eyes. The same technology was demonstrated to cause a sustained reduction of IOP by $3.8 \mathrm{mmHg}$ three weeks post-intravitreal injection of the vector in steroid-induced OHT murine models of glaucoma, compared to paired controls [119]. Although gene editing has remained in pre-clinical stages to date, it offers the alluring prospect of single and permanent intervention, which could aid in overcoming issues of patient non-compliance with therapy.

Carbonic anhydrase inhibitors (CAIs), such as acetazolamide, brinzolamide and dorzolamide, are widely used antiglaucoma medications that have been used for over 50 years [120]. They inhibit the carbonic anhydrase (CA) isoenzymes located in the non-pigmented ciliary epithelium, predominantly CA-II and CA-IV, decreasing aqueous humour production and hence reduce IOP [120]. There is increasing interest in developing novel nanoparticulate drug 
delivery systems for CAIs in order to overcome issues of poor bioavailability and patient concordance, and to minimise the risk of systemic adverse events [121-124].

Interestingly, in addition to decreasing aqueous humour production, CAIs have also been shown to cause vasodilation of retinal arteries and increase blood flow to the optic nerve head [125-127]. This could confer neuroprotective effects to RGCs. Various mechanisms, including increased $\mathrm{CO} 2$ and lower $\mathrm{pH}$ levels, have been proposed to explain this vasodilatory effect. However, CAI have been shown to cause vasodilation despite changes in extracellular $\mathrm{pH}$ and in the presence of hypercapnia, calling these theories into question $[128,129]$.

More recently, Dong et al [130] demonstrated that dorzolamide could mediate its vasodilatory effect by inhibiting $\mathrm{Ca}^{2+}$ entry through voltage-dependent $\mathrm{Ca}^{2+}$ channels in precontracted rabbit ciliary arteries. The exact mechanism through which CAIs cause vasodilation remains to be conclusively established. Once elucidated, this allow further study into CAIs' neuroprotective properties and their potential as dual-agent IOP-lowering and neurotprotective agents.

None of the major pharmacological therapies for glaucoma were purposed to target trabecular outflow via the trabecular meshwork (TM) specifically, although less commonly used commercially available therapies include Rhopressa and other ROCK-inhibitors [131]. More recently, however, ATP-sensitive potassium channels are gaining attention as potential therapeutic targets. ATP-sensitive Potassium $\left(\mathrm{K}_{\mathrm{ATP}}\right)$ Channels are hetero-octamers which are found on various tissues, including the heart, brain, pancreas and TM [132-136]. Their structure is highly cell-type specific, with the Kir6.1, Kir6.2 and SUR2B subunits expressed 
on TM cells [136]. $\mathrm{K}_{\mathrm{ATP}}$ channels are sensitive to intracellular concentrations of ATP and ADP and modulate membrane excitability of cells based on their metabolic status[137]. The $\mathrm{K}_{\mathrm{ATP}}$ channel openers, diazoxide, nicorandil and cromakalim have been demonstrated to be efficacious IOP-lowering drugs in human anterior segment perfusion cultures [138]. Subsequent in vivo studies by the same group have confirmed their IOP-lowering properties in mice and demonstrated the safety of this drug class, with no toxic side effects observed [138]. Some authors have also suggested that diazoxide may play a role in the purported excitotixcitiy theory as it has previously been demonstrated to significantly attentuate the degeneration of rat retinas exposed to glutamate, compared to controls [139]. However, the limited solubility of $\mathrm{K}_{\mathrm{ATP}}$ channel openers has made it difficult to develop a formulation that would be suitable for clinical trials. It will therefore be interesting to see whether nanotechnology can aid in overcoming this obstacle. It may also be interesting to further

study how exactly $\mathrm{K}_{\mathrm{ATP}}$ channel openers cause a reduction in IOP. Chowdhury et al recently demonstrated U0126 (a selective MEk1 and MEK2 inhibitor) to attenuate IOP reduction by both diazoxide and nicorandil in mice [140]. They therefore concluded that the ERK1/2 pathway may be important in IOP reduction by $\mathrm{K}_{\mathrm{ATP}}$ channel openers [140]. Studying the downstream effects of these pathways on IOP could hypothetically lead to the discovery of more specific therapeutic targets, overcoming issues of $\mathrm{K}_{\mathrm{ATP}}$ channel opener solubility.

\section{7) Targeting treatments to prevent retinal ganglion cell loss}

In order to target individuals with the aforementioned treatments to deliver personalised glaucoma therapy, we need to apply what is known about the pathophysiology of glaucoma to patients in clinical practice. Metabolomics is the scientific study of chemical processes involving metabolites. Nuclear magnetic resonance (NMR) and mass spectroscopy can be 
used to analyse in-vivo and in-vitro models and map out a "metabolic phenotype". It has been tested in both animal and human glaucoma models. This gives insight into all the biochemical processes occurring in a sample at any time, including the level of biofluids and tissues [141]. Metabolomics has previously identified altered lipid metabolism in POAG patients and been used to analyse changes in metabolites in the aqueous humour of rat models of chronic glaucoma $[142,143]$. In humans, the majority of data is cross-sectional, comparing patients with different disease status. These comparisons have identified alterations in vitamin Drelated metabolites, palmitoylcarnitine, hydroxyergocalciferol, terpenes and sphingolipids in glaucoma patients [142]. Through the study of metabolomics, we hope to gain a better understanding of the etiopathology of glaucoma, in particular the role of apoptosis and systemic influences in disease progression [144].

Our understanding of the pathophysiology of glaucoma has been enhanced using proton magnetic resonance (MR) spectroscopy and positron emission tomography (PET) [145]. PET imaging studies have demonstrated increased glial activity in the lateral geniculate nucleus of experimental glaucoma monkey models [146]. In addition, reduced glucose metabolism in the striate cortex and cholinergic abnormalities within the visual cortex of glaucoma patients have been demonstrated using proton MR spectroscopy $[147,148]$. These findings, taken together with future observations from metabolomic studies could aid in forming a more comprehensive understanding of the pathophysiology of glaucoma. This in turn could lead to the identification of new biomarkers and therapeutic targets, in addition to identifying high and low risk patients in order to guide treatment strategies.

The potential contribution of genetics to the pathophysiology of glaucoma has gained increasing interest within the last decade [149]. Recently, multitrait analysis of a genome- 
wide association study (GWAS) of 67,040 UK Biobank participants identified 49 new genetic loci associated with glaucoma [150]. From this analysis, a polygenic risk score (PRS) was developed and validated in an independent cohort. The score was able to predict glaucoma development as well as progression. Patients in the top PRS decile had a 14.9-fold increased risk of developing advanced glaucoma compared to the bottom decile (95\% CI 10.7-20.9) [150]. The adoption of a similar method of risk-stratifying patients to clinical practice could one day enable a more prompt and personalised approach to glaucoma therapy.

Earlier disease detection is to be required if we are to effectively apply neuroprotective therapies. Optical coherence tomography (OCT) is widely accepted as the structural imaging technique of choice for glaucomatous disease diagnosis and monitoring. It can be used to monitor the thickness of both circumpapillary and macular layers of the retina [151]. However, it is often not easy to differentiate between glaucomatous and age-related structural changes on OCT images [152], with RNFL thickness having been demonstrated to decrease by $2-2.97 \mu \mathrm{m}$ per decade [153-155]. Furthermore, RNFL thinning is thought to be detected only after significant amounts of RGC loss [156].

In-vivo imaging of processes leading to RGC loss could enable earlier detection of glaucoma, by enabling instantaneous representation of the rate of disease progression [157]. DARC (Detection of Apoptosing Retinal Cells) is a novel method aimed at visualising apoptotic retinal cells [158-160]. DARC uses fluorescently-labelled annexin A5, which has a high affinity for phosphatidylserine, exposed on the surface of cells in the early stages of apoptosis or stress [160] and is thought to remain in the retina for less than 24-hours. The Phase I trial deemed it safe for intravenous use in humans, with no serious adverse events and a short halflife of 10-36 minutes [160]. DARC may also have scope to inform on disease progression 
and other causes of retinal cell apoptosis including age-related macular degeneration, optic neuritis and Down's syndrome (as a model of amyloid-beta related dementia) [160]. Another approach is using a cell penetrating peptide probe, TCapQ [161]. This is designed to be optically silent until activated by cytoplasmic caspases 3 and 7, which are seen in apoptotic cells [162]. However, this technique is still in its preclinical stages. With retinal imaging continually improving in resolution, live cellular imaging is becoming possible using techniques such as adaptive optics[163]. It is hoped that the above techniques will further aid us to more accurately and promptly measure the rate at which patients are losing RGCs in order to provide future biomarkers for research, more accurately risk stratify patients, and deliver timely treatment to prevent loss of vision. 


\section{8) Conclusion}

It is clear that the pathogenesis of glaucoma is a complex network of genetic, biochemical and mechanical processes occurring in tandem with what is considered to be the spectrum of 'normal' ageing.-Therefore, a coordinated, multi-modal approach to preventing RGC loss is likely to be the most successful strategy to glaucoma therapy in the future. Within the past couple of decades several novel strategies have been suggested, however, the majority have failed to show efficacy in clinical trials. Through revisiting such strategies by exploring new routes of administration and formulations paired with the latest biomarkers, neuroprotective therapies and are now one step closer to translating to clinical practice. The critical question remains as to whether the future focus of this area of research remains with the preservation of existing RGCs or the regeneration of cells that can successfully interface with the central nervous system to restore lost vision.

\section{9) Expert opinion}

The pathophysiology of glaucoma is complex and multi-faceted. However, emerging fields such as microbiome-metabolomics, gene-editing and high-resolution imaging, could alter the landscape of future glaucoma research. With a greater understanding of the etiopathology of glaucoma as well as the role of apoptosis and systemic influences in disease progression, comes an increased likelihood of identifying new biomarkers and therapeutic targets.

Given the current and projected disease burden of glaucoma, motivation to find novel approaches to glaucoma therapy is higher than ever. Currently emerging novel therapeutic targets include $\mathrm{TrKB}$ receptors, $\mathrm{K}_{\mathrm{ATP}}$ and Piezo mechanosensitive channels and downstream targets thereof. Although in vivo studies have demonstrated the ability of some drug classes to preserve RGCs in various animal models, they are yet to be developed into formulations 
suitable for clinical trials. Whether these classes will ever translate into clinically viable therapeutic options therefore remains unknown.

One of the most important advances in ophthalmology in the last decade has been recognising the opportunities that Big Data and Artificial Intelligence (AI) can bring. It is early days yet for AI algorithms to be approved for clinical diagnostics, but already in glaucoma AI assessments have been utilised in disc photos, OCT, OCTA and perimetry. Moreover, there is recognition that these methodologies could enable better patient stratification, especially with respect to clinical trials. This will also be important in combining different technologies to provide personalised approaches to patient treatment. In the future, such modes may help in the design of individualised therapeutic regimens and involve newer and evolving surrogate and clinical endpoints.

Although both cell and gene therapies offer the alluring prospect of longer lasting treatments that could increase the bioavailability of neurotrophins whilst simultaneously overcoming issues of patient non-compliance, it is imperative that previous research is not completely discarded. Enhancing the neuroprotective effects of traditional glaucoma therapies and would not only save resources, but also lead to a timelier development of efficacious therapeutic strategies. Such therapies include the well-known interest surrounding alpha-2 agonists, but also prostaglandin analogues and carbonic anhydrase inhibitors. It may become possible to augment the neuroprotective effects of these drug classes, especially when combined with novel drug delivery and nanotechnology strategies. This may decrease the pressure to develop novel therapies and rather enable us to focus efforts on identifying early markers of disease progression, leading to more personalised and targeted management of glaucoma. 
The research potential in glaucoma is boundless. Beyond the drive to identify new therapeutic targets, there is also scope for better management through stratifying patients by risk of visual impairment and providing personalised therapy. This will naturally require huge research effort and may not become a reality for some time. However, emerging areas of research, including DARC and metabolomics are already beginning to provide a solid foundation for a new era of more personalised glaucoma management.

It is evident that the process of getting even the most promising of therapies from bench to bedside is a long, arduous and sometimes rather disheartening process, as demonstrated by the memantine trials. Thus far, no novel 'neuroprotective' glaucoma therapies have successfully translated to clinical practice. Barriers to successful translation to clinical practice include the long follow up required in a slowly progressing disease, a lack of highly sensitive and specific biomarkers with the power to control for confounders, differences between animal models and human disease and all underpinned by an incomplete understanding of the pathophysiology of glaucoma.

More realistic short-term goals may include the use of biomarkers, imaging techniques or genetics-based approaches to stratify patients by risk of visual impairment. Within the next five years, it is conceivable that the rate of RGC loss will dictate the management of individual patients, with more aggressive therapies being introduced earlier for those most at risk in order to maximise the chance of RGC survival.

Although radical changes in clinical practice remain unlikely, this is a very exciting time for glaucoma research including numerous novel modes and routes of treatment delivery. Within 
the next five years, we are likely to see a greater interest in the dual purposing of traditional glaucoma therapies, saving both time and resources in this field of research.

The natural progression for research from neuroprotection is neuroregeneration of RGCs. It will be interesting to see whether this alluring prospect becomes the new focus of research or whether the concept of neuroprotection still has a role to play in the future clinical landscape. Although still in relative infancy in the field of glaucoma, it is likely that this area of research will gain increasing attention over the next five years.

Overall, we are confident that within the next five years the trend in glaucoma research will move towards more a targeted and personalised approach to preventing visual impairment, with scope to further expand to the field of neuroregeneration in the more distant future.

\section{Funding:}

This manuscript is not funded.

\section{Declaration of Interest:}

MF Cordeiro is a named co-inventor on a granted patent EP 2231199B1 and published patent WO 2011055121A1 owned by UCL and related to DARC technology. The authors have no other relevant affiliations or financial involvement with any organization or entity with a financial interest in or financial conflict with the subject matter or materials discussed in the manuscript apart from those disclosed

\section{Reviewer Disclosures:}

Peer reviewers on this manuscript have no relevant financial or other relationships to disclose 


\section{$\underline{\text { References }}$}

Papers of special note have been highlighted as either of interest $\left({ }^{*}\right)$ or of considerable interest $\left({ }^{* *}\right)$ to readers.

[1] Casson RJ, Chidlow G, Wood JP, et al. Definition of glaucoma: clinical and experimental concepts. Clin. Experiment. Ophthalmol. [Internet]. 2012 [cited 2019 Jun 27];40:341-349. Available from: http://www.ncbi.nlm.nih.gov/pubmed/22356435.

[2] European Glaucoma Society Terminology and Guidelines for Glaucoma, 4th Edition Chapter 3: Treatment principles and options Supported by the EGS Foundation: Part 1: Foreword; Introduction; Glossary; Chapter 3 Treatment principles and options. Br. J. Ophthalmol. [Internet]. 2017/05/30. 2017;101:130-195. Available from: https://www.ncbi.nlm.nih.gov/pubmed/28559477.

[3] Quigley HA, Broman AT. The number of people with glaucoma worldwide in 2010 and 2020. Br. J. Ophthalmol. [Internet]. 2006;90:262 LP - 267. Available from: http://bjo.bmj.com/content/90/3/262.abstract.

[4] Comparison of glaucomatous progression between untreated patients with normaltension glaucoma and patients with therapeutically reduced intraocular pressures. Collaborative Normal-Tension Glaucoma Study Group. Am. J. Ophthalmol. [Internet]. 1998 [cited 2019 Jun 18];126:487-497. Available from: http://www.ncbi.nlm.nih.gov/pubmed/9780093.

[5] Boland M V, Ervin A-M, Friedman DS, et al. Comparative effectiveness of treatments for open-angle glaucoma: a systematic review for the U.S. Preventive Services Task Force. Ann. Intern. Med. 2013;158:271-279.

[6] Lopez Sanchez MIG, Crowston JG, Mackey DA, et al. Emerging Mitochondrial 
Therapeutic Targets in Optic Neuropathies. Pharmacol. Ther. [Internet]. 2016 [cited 2019 Jul 10];165:132-152. Available from:

https:/www.sciencedirect.com/science/article/pii/S0163725816300948?via\%3Dihub.

[7] Caleo M, Menna E, Chierzi S, et al. Brain-derived neurotrophic factor is an anterograde survival factor in the rat visual system [Internet]. 2000 [cited 2019 Jun 27]. Available from: https://core.ac.uk/download/pdf/82289033.pdf.

[8] Wiggs JL, Pasquale LR. Genetics of glaucoma. Hum. Mol. Genet. 2017;26:R21-R27.

[9] Casson RJ. Possible role of excitotoxicity in the pathogenesis of glaucoma. Clin. Exp. Ophthalmol. [Internet]. 2006 [cited 2019 Aug 7];34:54-63. Available from: http://www.ncbi.nlm.nih.gov/pubmed/16451260.

[10] Wang R, Reddy PH. Role of Glutamate and NMDA Receptors in Alzheimer's Disease. J. Alzheimers. Dis. 2017;57:1041-1048.

[11] Sisk DR, Kuwabara T. Histologic changes in the inner retina of albino rats following intravitreal injection of monosodium L-glutamate. Graefes Arch. Clin. Exp. Ophthalmol. 1985;223:250-258.

[12] Levy DI, Lipton SA. Comparison of delayed administration of competitive and uncompetitive antagonists in preventing NMDA receptor-mediated neuronal death. Neurology. 1990;40:852-855.

[13] Kemp JA, McKernan RM. NMDA receptor pathways as drug targets. Nat. Neurosci. [Internet]. 2002;5 Suppl:1039-1042. Available from:

https://pubmed.ncbi.nlm.nih.gov/12403981.

[14] Park SH, Kim JH, Kim YH, et al. Expression of neuronal nitric oxide synthase in the retina of a rat model of chronic glaucoma. Vision Res. [Internet]. 2007;47:2732-2740. Available from: http://europepmc.org/abstract/MED/17825345.

[15] Dong X, Wang Y, Qin Z. Molecular mechanisms of excitotoxicity and their relevance 
to pathogenesis of neurodegenerative diseases. Acta Pharmacol. Sin. [Internet]. 2009 [cited 2019 Aug 7];30:379-387. Available from:

http://www.ncbi.nlm.nih.gov/pubmed/19343058.

[16] Vrabec JP, Levin LA. The neurobiology of cell death in glaucoma. Eye (Lond). [Internet]. 2007;21 Suppl 1:S11-S14. Available from: https://pubmed.ncbi.nlm.nih.gov/18157171.

[17] Do Y-J, Sul J-W, Jang K-H, et al. A novel RIPK1 inhibitor that prevents retinal degeneration in a rat glaucoma model. Exp. Cell Res. [Internet]. 2017/08/09. 2017;359:30-38. Available from: https://pubmed.ncbi.nlm.nih.gov/28803066.

[18] Russo R, Varano GP, Adornetto A, et al. Retinal ganglion cell death in glaucoma: Exploring the role of neuroinflammation. Eur. J. Pharmacol. [Internet]. 2016 [cited 2019 Jun 13];787:134-142. Available from: https://linkinghub.elsevier.com/retrieve/pii/S0014299916302047.

[19] Salt TE, Cordeiro MF. Glutamate excitotoxicity in glaucoma: throwing the baby out with the bathwater? Eye (Lond). [Internet]. 2005/06/10. 2006;20:730-732. Available from: https://pubmed.ncbi.nlm.nih.gov/15951750.

[20] Shah RS, Lee H-G, Xiongwei Z, et al. Current approaches in the treatment of Alzheimer's disease. Biomed. Pharmacother. [Internet]. 2008 [cited 2019 Aug 8];62:199-207. Available from:

https://www.sciencedirect.com/science/article/pii/S0753332208000401.

[21] Celiker H, Yuksel N, Solakoglu S, et al. Neuroprotective Effects of Memantine in the Retina of Glaucomatous Rats: An Electron Microscopic Study. J. Ophthalmic Vis. Res. [Internet]. 2016;11:174-182. Available from: https://www.ncbi.nlm.nih.gov/pubmed/27413498.

[22] Vorwerk CK, Lipton SA, Zurakowski D, et al. Chronic low-dose glutamate is toxic to 
retinal ganglion cells. Toxicity blocked by memantine. Invest. Ophthalmol. Vis. Sci. $1996 ; 37: 1618-1624$.

[23] Hare W, WoldeMussie E, Lai R, et al. Efficacy and safety of memantine, an NMDAtype open-channel blocker, for reduction of retinal injury associated with experimental glaucoma in rat and monkey. Surv. Ophthalmol. 2001;45 Suppl 3:S284-9; discussion S295-6.

[24] **Weinreb RN, Liebmann JM, Cioffi GA, et al. Oral Memantine for the Treatment of Glaucoma: Design and Results of 2 Randomized, PlaceboControlled, Phase 3 Studies. Ophthalmology. 2018;125:1874-1885.

**Summary of two large randomised studies looking at effectiveness of daily doses of oral memantine. Both trials, rather disappointingly, failed ot show a significant difference between treatment and control arms. These trials were a turning point for the research approach for memantine.

[25] Carter-Dawson L, Crawford MLJ, Harwerth RS, et al. Vitreal glutamate concentration in monkeys with experimental glaucoma. Invest. Ophthalmol. Vis. Sci. 2002;43:26332637.

[26] Sanchez-Lopez E, Egea MA, Davis BM, et al. Memantine-Loaded PEGylated Biodegradable Nanoparticles for the Treatment of Glaucoma. Small. 2018;14.

[27] Lee D, Kim K-Y, Noh YH, et al. Brimonidine blocks glutamate excitotoxicity-induced oxidative stress and preserves mitochondrial transcription factor a in ischemic retinal injury. PLoS One. 2012;7:e47098.

[28] Nizari S, Guo L, Davis BM, et al. Non-amyloidogenic effects of alpha2 adrenergic agonists: implications for brimonidine-mediated neuroprotection. Cell Death Dis. 2016;7:e2514

[29] **Krupin T, Liebmann JM, Greenfield DS, et al. A randomized trial of brimonidine versus timolol in preserving visual function: results from the Low- 
Pressure Glaucoma Treatment Study. Am. J. Ophthalmol. 2011;151:671-681.

**Study exploring excitotoxicity. Suggests neuroprotective efficacy of Brimonidine, with only $9.1 \%$ of patients in the brimonidine group progressing in comparison to $39.2 \%$ in the timolol group.

[30] Cordeiro MF, Levin LA. Clinical evidence for neuroprotection in glaucoma. Am. J. Ophthalmol. [Internet]. 2011;152:715-716. Available from: https://www.ncbi.nlm.nih.gov/pubmed/22017839.

[31] Matteucci A, Frank C, Domenici MR, et al. Curcumin treatment protects rat retinal neurons against excitotoxicity: effect on N-methyl-D: -aspartate-induced intracellular $\mathrm{Ca}(2+)$ increase. Exp. brain Res. 2005;167:641-648.

[32] Trujillo J, Granados-Castro LF, Zazueta C, et al. Mitochondria as a target in the therapeutic properties of curcumin. Arch. Pharm. (Weinheim). 2014;347:873-884.

[33] Wang H-M, Zhao Y-X, Zhang S, et al. PPARgamma agonist curcumin reduces the amyloid-beta-stimulated inflammatory responses in primary astrocytes. J. Alzheimers. Dis. 2010;20:1189-1199.

[34] Mallozzi C, Parravano M, Gaddini L, et al. Curcumin Modulates the NMDA Receptor Subunit Composition Through a Mechanism Involving CaMKII and Ser/Thr Protein Phosphatases. Cell. Mol. Neurobiol. [Internet]. 2018;38:1315-1320. Available from: http://ovidsp.ovid.com/ovidweb.cgi?T $=J S \& P A G E=$ reference $\& D=$ med13\&NEWS $=\mathrm{N}$ $\& \mathrm{AN}=29846839$.

[35] Dei Cas M, Ghidoni R. Dietary Curcumin: Correlation between Bioavailability and Health Potential. Nutrients [Internet]. 2019;11:2147. Available from: https://pubmed.ncbi.nlm.nih.gov/31500361.

[36] Davis BM, Pahlitzsch M, Guo L, et al. Topical Curcumin Nanocarriers are Neuroprotective in Eye Disease. Sci. Rep. [Internet]. 2018 [cited 2019 Jun 
14];8:11066. Available from: http://www.ncbi.nlm.nih.gov/pubmed/30038334.

[37] Bannister AJ, Kouzarides T. Regulation of chromatin by histone modifications [Internet]. Cell Res. Nature Publishing Group; 2011 [cited 2020 Jul 8]. p. 381-395. Available from: www.cell-research.com.

[38] Pelzel HR, Schlamp CL, Nickells RW. Histone H4 deacetylation plays a critical role in early gene silencing during neuronal apoptosis. BMC Neurosci. [Internet]. 2010 [cited 2020 Jul 8];11:1-20. Available from: https://link.springer.com/articles/10.1186/14712202-11-62.

[39] Schluter A, Aksan B, Fioravanti R, et al. Histone Deacetylases Contribute to Excitotoxicity-Triggered Degeneration of Retinal Ganglion Cells In Vivo. Mol. Neurobiol. [Internet]. 2019; Available from: http://ovidsp.ovid.com/ovidweb.cgi? $\mathrm{T}=\mathrm{JS} \& \mathrm{PAGE}=$ reference $\& \mathrm{D}=$ medp\&NEWS $=\mathrm{N} \&$ $\mathrm{AN}=31161423$.

[40] Zala D, Hinckelmann M-V, Yu H, et al. Vesicular Glycolysis Provides On-Board Energy for Fast Axonal Transport. Cell [Internet]. 2013 [cited 2019 Jul 10];152:479_ 491. Available from: https://www.sciencedirect.com/science/article/pii/S0092867412015516.

[41] Ray PD, Huang B-W, Tsuji Y. Reactive oxygen species (ROS) homeostasis and redox regulation in cellular signaling. Cell. Signal. [Internet]. 2012 [cited 2019 Jul 10];24:981-990. Available from:

https://www.sciencedirect.com/science/article/pii/S0898656812000137.

[42] Ames BN, Shigenaga MK, Hagen TM. Oxidants, antioxidants, and the degenerative diseases of aging (cancer/mutation/endogenous DNA adducts/oxygen radicals) [Internet]. Proc. Natl. Acad. Sci. USA. 1993 [cited 2019 Jul 10]. Available from: https://www.pnas.org/content/pnas/90/17/7915.full.pdf. 
[43] Larsson oran. Somatic Mitochondrial DNA Mutations in Mammalian Aging. Annu. Rev. Biochem [Internet]. 2010 [cited 2019 Jul 10];79:683-706. Available from: www.annualreviews.org.

[44] Schmelzer C, Lindner I, Rimbach G, et al. Functions of coenzyme Q10 in inflammation and gene expression. Biofactors [Internet]. 2008 [cited 2019 Aug 16];32:179-183. Available from: http://www.ncbi.nlm.nih.gov/pubmed/19096114.

[45] Nucci C, Tartaglione R, Cerulli A, et al. Retinal Damage Caused by High Intraocular Pressure-Induced Transient Ischemia is Prevented by Coenzyme Q10 in Rat. Int. Rev. Neurobiol. [Internet]. 2007 [cited 2019 Jul 10];82:397-406. Available from: https:/www.sciencedirect.com/science/article/pii/S0074774207820228?via\%3Dihub.

[46] Somayajulu M, McCarthy S, Hung M, et al. Role of mitochondria in neuronal cell death induced by oxidative stress; neuroprotection by Coenzyme Q10. Neurobiol. Dis. [Internet]. 2005 [cited 2019 Aug 16];18:618-627. Available from: http://www.ncbi.nlm.nih.gov/pubmed/15755687.

[47] Lee D, Shim MS, Kim K-Y, et al. Coenzyme Q10 inhibits glutamate excitotoxicity and oxidative stress-mediated mitochondrial alteration in a mouse model of glaucoma. Invest. Ophthalmol. Vis. Sci. [Internet]. 2014 [cited 2019 Aug 16];55:993-1005. Available from: http://www.ncbi.nlm.nih.gov/pubmed/24458150.

[48] Davis BM, Tian K, Pahlitzsch M, et al. Topical Coenzyme Q10 demonstrates mitochondrial-mediated neuroprotection in a rodent model of ocular hypertension. Mitochondrion [Internet]. 2017 [cited 2019 Jul 10];36:114-123. Available from: http://www.ncbi.nlm.nih.gov/pubmed/28549843.

[49] Parisi V, Centofanti M, Gandolfi S, et al. Effects of Coenzyme Q10 in Conjunction With Vitamin E on Retinal-evoked and Cortical-evoked Responses in Patients With Open-angle Glaucoma. 2012 [cited 2019 Jul 10]; Available from: 
www.glaucomajournal.com.

[50] Ozates S, Elgin KU, Yilmaz NS, et al. Evaluation of oxidative stress in pseudoexfoliative glaucoma patients treated with and without topical coenzyme Q10 and vitamin E. Eur. J. Ophthalmol. [Internet]. 2018/06/05. 2019;29:196-201. Available from: https://pubmed.ncbi.nlm.nih.gov/29869538.

[51] Quaranta L, Riva I, Biagioli E, et al. Evaluating the Effects of an Ophthalmic Solution of Coenzyme Q10 and Vitamin E in Open-Angle Glaucoma Patients: A Study Protocol. Adv. Ther. [Internet]. 2019;36:2506-2514. Available from: http://europepmc.org/abstract/MED/31301054.

[52] Grieb P. Neuroprotective properties of citicoline: facts, doubts and unresolved issues. CNS Drugs [Internet]. 2014 [cited 2019 Aug 13];28:185-193. Available from: http://www.ncbi.nlm.nih.gov/pubmed/24504829.

[53] Alvarez XA, Mouzo R, Pichel V, et al. Double-blind placebo-controlled study with citicoline in APOE genotyped Alzheimer's disease patients. Effects on cognitive performance, brain bioelectrical activity and cerebral perfusion. Methods Find. Exp. Clin. Pharmacol. [Internet]. 1999 [cited 2019 Aug 13];21:633-644. Available from: http://www.ncbi.nlm.nih.gov/pubmed/10669911.

[54] Eberhardt R, Birbamer G, Gerstenbrand F, et al. Citicoline in the treatment of Parkinson's disease. Clin. Ther. [Internet]. [cited 2019 Aug 13];12:489-495. Available from: http://www.ncbi.nlm.nih.gov/pubmed/2289218.

[55] Secades JJ. Citicoline: pharmacological and clinical review, 2010 update. Rev. Neurol. [Internet]. 2011 [cited 2019 Aug 13];52 Suppl 2:S1-S62. Available from: http://www.ncbi.nlm.nih.gov/pubmed/21432836.

[56] Fresina M, Dickmann A, Salerni A, et al. Effect of oral CDP-choline on visual function in young amblyopic patients. Graefe's Arch. Clin. Exp. Ophthalmol. 
[Internet]. 2008 [cited 2019 Aug 13];246:143-150. Available from:

http://www.ncbi.nlm.nih.gov/pubmed/17638004.

[57] Faiq MA, Wollstein G, Schuman JS, et al. Cholinergic nervous system and glaucoma: From basic science to clinical applications. Prog. Retin. Eye Res. [Internet]. 2019;72:100767. Available from:

http://www.sciencedirect.com/science/article/pii/S1350946218300752.

[58] Oshitari T, Fujimoto N, Adachi-Usami E. Citicoline has a protective effect on damaged retinal ganglion cells in mouse culture retina. Neuroreport [Internet]. 2002 [cited 2019 Aug 13];13:2109-2111. Available from: http://www.ncbi.nlm.nih.gov/pubmed/12438935.

[59] Schuettauf F, Rejdak R, Thaler S, et al. Citicoline and lithium rescue retinal ganglion cells following partial optic nerve crush in the rat. Exp. Eye Res. [Internet]. 2006 [cited 2019 Aug 13];83:1128-1134. Available from: https://www.sciencedirect.com/science/article/pii/S0014483506002879?via\%3Dihub.

[60] Parisi V, Centofanti M, Ziccardi L, et al. Treatment with citicoline eye drops enhances retinal function and neural conduction along the visual pathways in open angle glaucoma. Graefe's Arch. Clin. Exp. Ophthalmol. [Internet]. 2015 [cited 2019 Aug 13];253:1327-1340. Available from: http://link.springer.com/10.1007/s00417-0153044-9.

[61] Parisi V, Coppola G, Centofanti M, et al. Evidence of the neuroprotective role of citicoline in glaucoma patients. Prog. Brain Res. [Internet]. 2008;173:541-554. Available from: https://pubmed.ncbi.nlm.nih.gov/18929133.

[62] Casson RJ, Han G, Ebneter A, et al. Glucose-induced temporary visual recovery in primary open-angle glaucoma: A double-blind, randomized study. Ophthalmology. 2014;121:1203-1211. 
[63] Harun-Or-Rashid M, Pappenhagen N, Zubricky R, et al. MCT2 overexpression rescues metabolic vulnerability and protects retinal ganglion cells in two models of glaucoma. Neurobiol. Dis. 2020;141:104944.

[64] Insulin signalling promotes dendrite and synapse regeneration and restores circuit function after axonal injury | Brain | Oxford Academic [Internet]. [cited 2020 Jul 8]. Available from: https://academic.oup.com/brain/article/141/7/1963/5039589.

[65] Kass MA, Heuer DK, Higginbotham EJ, et al. The Ocular Hypertension Treatment Study. Arch. Ophthalmol. [Internet]. 2002 [cited 2019 Aug 15];120:701. Available from: http://www.ncbi.nlm.nih.gov/pubmed/12049574.

[66] Aguayo AJ, Clarke DB, Jelsma TN, et al. Effects of neurotrophins on the survival and regrowth of injured retinal neurons. Ciba Found. Symp. 1996;196:135-138.

[67] Sampaio TB, Savall AS, Gutierrez MEZ, et al. Neurotrophic factors in Alzheimer's and Parkinson's diseases: implications for pathogenesis and therapy. Neural Regen. Res. [Internet]. 2017;12:549-557. Available from: https://pubmed.ncbi.nlm.nih.gov/28553325.

[68] Razavi S, Nazem G, Mardani M, et al. Neurotrophic factors and their effects in the treatment of multiple sclerosis. Adv. Biomed. Res. [Internet]. 2015;4:53. Available from: https://pubmed.ncbi.nlm.nih.gov/25802822.

[69] Inanc Tekin M, Sekeroglu MA, Demirtas C, et al. Brain-Derived Neurotrophic Factor in Patients With Age-Related Macular Degeneration and Its Correlation With Retinal Layer Thicknesses. Invest. Ophthalmol. Vis. Sci. [Internet]. 2018;59:2833-2840. Available from: http://europepmc.org/abstract/MED/30025135.

[70] Kowiański P, Lietzau G, Czuba E, et al. BDNF: A Key Factor with Multipotent Impact on Brain Signaling and Synaptic Plasticity. Cell. Mol. Neurobiol. [Internet]. 2018 [cited 2019 Jul 10];38:579-593. Available from: 
http://www.ncbi.nlm.nih.gov/pubmed/28623429.

[71] Takihara $\mathrm{Y}$, Inatani M, Hayashi $\mathrm{H}$, et al. Dynamic imaging of axonal transport in living retinal ganglion cells in vitro. Invest. Ophthalmol. Vis. Sci. 2011;52:3039-3045.

[72] Pease ME, McKinnon SJ, Quigley HA, et al. Obstructed axonal transport of BDNF and its receptor TrkB in experimental glaucoma. Invest. Ophthalmol. Vis. Sci. 2000;41:764-774.

[73] Chen $\mathrm{H}$, Weber AJ. BDNF enhances retinal ganglion cell survival in cats with optic nerve damage. Invest. Ophthalmol. Vis. Sci. 2001;42:966-974.

[74] Peinado-Ramon P, Salvador M, Villegas-Perez MP, et al. Effects of axotomy and intraocular administration of NT-4, NT-3, and brain-derived neurotrophic factor on the survival of adult rat retinal ganglion cells. A quantitative in vivo study. Invest. Ophthalmol. Vis. Sci. 1996;37:489-500.

[75] Ko ML, Hu DN, Ritch R, et al. The combined effect of brain-derived neurotrophic factor and a free radical scavenger in experimental glaucoma. Invest. Ophthalmol. Vis. Sci. 2000;41:2967-2971.

[76] Martin KRG, Quigley HA, Zack DJ, et al. Gene therapy with brain-derived neurotrophic factor as a protection: retinal ganglion cells in a rat glaucoma model. Invest. Ophthalmol. Vis. Sci. [Internet]. 2003;44:4357-4365. Available from: https://pubmed.ncbi.nlm.nih.gov/14507880.

[77] Bai Y, Xu J, Brahimi F, et al. An agonistic TrkB mAb causes sustained TrkB activation, delays RGC death, and protects the retinal structure in optic nerve axotomy and in glaucoma. Invest. Ophthalmol. Vis. Sci. [Internet]. 2010/03/31. 2010;51:47224731. Available from: https://pubmed.ncbi.nlm.nih.gov/20357199.

[78] Gupta VK, You Y, Klistorner A, et al. Shp-2 regulates the TrkB receptor activity in the retinal ganglion cells under glaucomatous stress. Biochim. Biophys. Acta - Mol. Basis 
Dis. $2012 ; 1822: 1643-1649$.

[79] Gupta V, Chitranshi N, You Y, et al. Biochemical and Biophysical Research Communications Brain derived neurotrophic factor is involved in the regulation of glycogen synthase kinase 3 b ( GSK3 b ) signalling. Biochem. Biophys. Res. Commun. 2014;454:381-386.

[80] Kaplan DR, Miller FD. Neurotrophin signal transduction in the nervous system. Curr. Opin. Neurobiol. [Internet]. 2000;10:381-391. Available from: http://www.sciencedirect.com/science/article/pii/S0959438800000921.

[81] Nebbioso M, Rusciano D, Pucci B, et al. Treatment of glaucomatous patients by means of food supplement to reduce the ocular discomfort: a double blind randomized trial.

[82] Meyer-Franke A, Wilkinson GA, Kruttgen A, et al. Depolarization and cAMP elevation rapidly recruit TrkB to the plasma membrane of CNS neurons. Neuron. 1998;21:681-693.

[83] Nakahashi T, Fujimura H, Altar CA, et al. Vascular endothelial cells synthesize and secrete brain-derived neurotrophic factor. FEBS Lett. [Internet]. 2000 [cited $2020 \mathrm{Jul}$ 6];470:113-117. Available from: https://febs.onlinelibrary.wiley.com/doi/full/10.1016/S0014-5793\%2800\%2901302-8.

[84] Adenylyl Cyclase in Human and Bovine Trabecular Meshwork - PubMed [Internet]. [cited 2020 Jul 6]. Available from: https://pubmed.ncbi.nlm.nih.gov/8103041/.

[85] Mutolo MG, Albanese G, Rusciano D, et al. Oral Administration of Forskolin, Homotaurine, Carnosine, and Folic Acid in Patients with Primary Open Angle Glaucoma: Changes in Intraocular Pressure, Pattern Electroretinogram Amplitude, and Foveal Sensitivity. J. Ocul. Pharmacol. Ther. [Internet]. 2016 [cited 2020 Jul 7];32:178-183. Available from: http://www.liebertpub.com/doi/10.1089/jop.2015.0121 
[86] Liu C, Chan CB, Ye K. 7,8-dihydroxyflavone, a small molecular TrkB agonist, is useful for treating various BDNF-implicated human disorders. Transl. Neurodegener. [Internet]. 2016;5:2. Available from:

https://www.ncbi.nlm.nih.gov/pubmed/26740873.

[87] Gupta VK, You Y, Li JC, et al. Protective effects of 7,8-dihydroxyflavone on retinal ganglion and RGC-5 cells against excitotoxic and oxidative stress. J. Mol. Neurosci. 2013;49:96-104.

[88] Ali Shariati M, Kumar V, Yang T, et al. A Small Molecule TrkB Neurotrophin Receptor Partial Agonist as Possible Treatment for Experimental Nonarteritic Anterior Ischemic Optic Neuropathy. Curr. Eye Res. [Internet]. 2018/10/01. 2018;43:14891499. Available from: https://pubmed.ncbi.nlm.nih.gov/30273053.

[89] Bongioanni P, Reali C, Sogos V. Ciliary neurotrophic factor (CNTF) for amyotrophic lateral sclerosis/motor neuron disease. Cochrane database Syst. Rev. [Internet]. 2004;CD004302-CD004302. Available from: https://pubmed.ncbi.nlm.nih.gov/15266526.

[90] Whone A, Luz M, Boca M, et al. Randomized trial of intermittent intraputamenal glial cell line-derived neurotrophic factor in Parkinson's disease. Brain [Internet]. 2019;142:512-525. Available from: https://pubmed.ncbi.nlm.nih.gov/30808022.

[91] Pease ME, Zack DJ, Berlinicke C, et al. Effect of CNTF on retinal ganglion cell survival in experimental glaucoma. Invest. Ophthalmol. Vis. Sci. 2009;50:2194-2200.

[92] Dittrich F, Thoenen H, Sendtner M. Ciliary neurotrophic factor: pharmacokinetics and acute-phase response in rat. Ann. Neurol. 1994;35:151-163.

[93] Flachsbarth K, Jankowiak W, Kruszewski K, et al. Pronounced synergistic neuroprotective effect of GDNF and CNTF on axotomized retinal ganglion cells in the adult mouse. Exp. Eye Res. 2018;176:258-265. 
[94] Canesi M, Giordano R, Lazzari L, et al. Finding a new therapeutic approach for nooption Parkinsonisms: mesenchymal stromal cells for progressive supranuclear palsy.

J. Transl. Med. [Internet]. 2016;14:127. Available from:

https://www.ncbi.nlm.nih.gov/pubmed/27160012.

[95] Kang JM, Yeon BK, Cho S-J, et al. Stem Cell Therapy for Alzheimer's Disease: A Review of Recent Clinical Trials. J. Alzheimers. Dis. 2016;54:879-889.

[96] Kauper K, McGovern C, Sherman S, et al. Two-Year Intraocular Delivery of Ciliary Neurotrophic Factor by Encapsulated Cell Technology Implants in Patients with Chronic Retinal Degenerative Diseases. Invest. Ophthalmol. Vis. Sci. [Internet]. 2012;53:7484-7491. Available from: https://doi.org/10.1167/iovs.12-9970.

[97] *Osborne A, Khatib TZ, Songra L, et al. Neuroprotection of retinal ganglion cells by a novel gene therapy construct that achieves sustained enhancement of brainderived neurotrophic factor/tropomyosin-related kinase receptor-B signaling. Cell Death Dis. [Internet]. 2018;9:1007. Available from: https://pubmed.ncbi.nlm.nih.gov/30258047.

*Study evaluating the use of adeno-associate virus gene therapy to increase BDNF production in rodent models

[98] Guo L, Moss SE, Alexander RA, et al. Retinal ganglion cell apoptosis in glaucoma is related to intraocular pressure and IOP-induced effects on extracellular matrix. Invest. Ophthalmol. Vis. Sci. [Internet]. 2005;46:175-182. Available from: https://www.ncbi.nlm.nih.gov/pubmed/15623771.

[99] Balaratnasingam C, Morgan WH, Bass L, et al. Axonal Transport and Cytoskeletal Changes in the Laminar Regions after Elevated Intraocular Pressure. Investig. Opthalmology Vis. Sci. [Internet]. 2007 [cited 2019 Aug 15];48:3632. Available from: http://www.ncbi.nlm.nih.gov/pubmed/17652733.

[100] Quigley HA, McKinnon SJ, Zack DJ, et al. Retrograde axonal transport of BDNF in 
retinal ganglion cells is blocked by acute IOP elevation in rats. Invest. Ophthalmol. Vis. Sci. [Internet]. 2000;41:3460-3466. Available from:

https://www.ncbi.nlm.nih.gov/pubmed/11006239.

[101] Wiederholt M, Sturm A, Lepple-Wienhues A. Relaxation of trabecular meshwork and ciliary muscle by release of nitric oxide. Invest. Ophthalmol. Vis. Sci. [Internet]. 1994;35:2515-2520. Available from: https://www.ncbi.nlm.nih.gov/pubmed/7512945.

[102] Schneemann A, Dijkstra BG, van den Berg TJ, et al. Nitric oxide/guanylate cyclase pathways and flow in anterior segment perfusion. Graefes Arch. Clin. Exp.

Ophthalmol. [Internet]. 2002/10/17. 2002;240:936-941. Available from:

https://www.ncbi.nlm.nih.gov/pubmed/12486517.

[103] Calabrese V, Mancuso C, Calvani M, et al. Nitric oxide in the central nervous system: neuroprotection versus neurotoxicity. Nat. Rev. Neurosci. [Internet]. 2007;8:766-775. Available from: https://pubmed.ncbi.nlm.nih.gov/17882254.

[104] Kotikoski H, Alajuuma P, Moilanen E, et al. Comparison of Nitric Oxide Donors in Lowering Intraocular Pressure in Rabbits: Role of Cyclic GMP. J. Ocul. Pharmacol. Ther. [Internet]. 2002;18:11-23. Available from: https://doi.org/10.1089/108076802317233171.

[105] Wizemann AJ, Wizemann V. Organic nitrate therapy in glaucoma. Am. J. Ophthalmol. [Internet]. 1980;90:106-109. Available from: http://europepmc.org/abstract/MED/6772033.

[106] Dismuke WM, Liang J, Overby DR, et al. Concentration-related effects of nitric oxide and endothelin-1 on human trabecular meshwork cell contractility. Exp. Eye Res. [Internet]. 2013/12/27. 2014;120:28-35. Available from: https://www.ncbi.nlm.nih.gov/pubmed/24374036.

[107] Hu C, Sun J, Zhang Y, et al. Local Delivery and Sustained-Release of Nitric Oxide 
Donor Loaded in Mesoporous Silica Particles for Efficient Treatment of Primafile://Users/marykelada/Downloads/12486517.ris

file://Users/marykelada/Downloads/7512945.ris ry Open-Angle Glaucoma. Adv. Healthc. Mater. [Internet]. 2018/11/02. 2018;7:e1801047-e1801047. Available from: https://www.ncbi.nlm.nih.gov/pubmed/30387326.

[108] Weinreb RN, Ong T, Scassellati Sforzolini B, et al. A randomised, controlled comparison of latanoprostene bunod and latanoprost $0.005 \%$ in the treatment of ocular hypertension and open angle glaucoma: the VOYAGER study. Br. J. Ophthalmol. [Internet]. 2015;99:738 LP - 745. Available from: http://bjo.bmj.com/content/99/6/738.abstract.

[109] Hoy SM. Latanoprostene Bunod Ophthalmic Solution 0.024\%: A Review in OpenAngle Glaucoma and Ocular Hypertension. Drugs [Internet]. 2018;78:773-780. Available from: https://www.ncbi.nlm.nih.gov/pubmed/29761382.

[110] Li F, Huang W, Zhang X. Efficacy and safety of different regimens for primary openangle glaucoma or ocular hypertension: a systematic review and network metaanalysis. Acta Ophthalmol. [Internet]. 2017/11/16. 2018;96:e277-e284. Available from: https://www.ncbi.nlm.nih.gov/pubmed/29144028.

[111] Kanamori A, Naka M, Fukuda M, et al. Latanoprost protects rat retinal ganglion cells from apoptosis in vitro and in vivo. Exp. Eye Res. 2009;88:535-541.

[112] Yamagishi R, Aihara M, Araie M. Neuroprotective effects of prostaglandin analogues on retinal ganglion cell death independent of intraocular pressure reduction. Exp. Eye Res. 2011;93:265-270.

[113] Drago F, Valzelli S, Emmi I, et al. Latanoprost exerts neuroprotective activity in vitro and in vivo. Exp. Eye Res. 2001;72:479-486.

[114] Nakanishi Y, Nakamura M, Mukuno H, et al. Latanoprost rescues retinal neuro-glial 
cells from apoptosis by inhibiting caspase-3, which is mediated by $\mathrm{p} 44 / \mathrm{p} 42$ mitogenactivated protein kinase. Exp. Eye Res. 2006;83:1108-1117.

[115] Gupta SK, Niranjan D G, Agrawal SS, et al. Recent advances in pharmacotherapy of glaucoma. Indian J. Pharmacol. [Internet]. 2008;40:197-208. Available from: https://www.ncbi.nlm.nih.gov/pubmed/20040958.

[116] Fukuda M, Sasaki H. The transcorneal penetration of commercial ophthalmic formulations containing timolol maleate in rabbit eyes. J. Ocul. Pharmacol. Ther. $2015 ; 31: 57-60$.

[117] Farkouh A, Frigo P, Czejka M. Systemic side effects of eye drops: a pharmacokinetic perspective. Clin. Ophthalmol. [Internet]. 2016;10:2433-2441. Available from: https://www.ncbi.nlm.nih.gov/pubmed/27994437.

[118] Shokry M, Hathout RM, Mansour S. Exploring gelatin nanoparticles as novel nanocarriers for Timolol Maleate: Augmented in-vivo efficacy and safe histological profile. Int. J. Pharm. [Internet]. 2018;545:229-239. Available from: http://www.sciencedirect.com/science/article/pii/S0378517318302874.

[119] Wu J, Bell OH, Copland DA, et al. Gene Therapy for Glaucoma by Ciliary Body Aquaporin 1 Disruption Using CRISPR-Cas9. Mol. Ther. 2020;28:820-829.

[120] Pastorekova S, Parkkila S, Pastorek J, et al. Carbonic Anhydrases: Current State of the Art, Therapeutic Applications and Future Prospects. J. Enzyme Inhib. Med. Chem. [Internet]. 2004;19:199-229. Available from:

https://doi.org/10.1080/14756360410001689540.

[121] Manchanda S, Sahoo PK. Topical delivery of acetazolamide by encapsulating in mucoadhesive nanoparticles. Asian J. Pharm. Sci. [Internet]. 2017;12:550-557. Available from: http://www.sciencedirect.com/science/article/pii/S1818087616302902. 
[122] Rathod L V, Kapadia R, Sawant KK. A novel nanoparticles impregnated ocular insert for enhanced bioavailability to posterior segment of eye: In vitro, in vivo and stability studies. Mater. Sci. Eng. C [Internet]. 2017;71:529-540. Available from: http://www.sciencedirect.com/science/article/pii/S0928493116312176.

[123] Abdel-Rashid RS, Helal DA, Omar MM, et al. Nanogel loaded with surfactant based nanovesicles for enhanced ocular delivery of acetazolamide. Int. J. Nanomedicine [Internet]. 2019;14:2973-2983. Available from:

https://pubmed.ncbi.nlm.nih.gov/31118616.

[124] Salama HA, Ghorab M, Mahmoud AA, et al. PLGA Nanoparticles as Subconjunctival Injection for Management of Glaucoma. AAPS PharmSciTech [Internet]. 2017;18:2517-2528. Available from: https://doi.org/10.1208/s12249-017-0710-8.

[125] Haustein M, Spoerl E, Boehm AG. The effect of acetazolamide on different ocular vascular beds. Graefes Arch. Clin. Exp. Ophthalmol. 2013;251:1389-1398.

[126] Harris A, Arend O, Kagemann L, et al. Dorzolamide, visual function and ocular hemodynamics in normal-tension glaucoma. J. Ocul. Pharmacol. Ther. 1999;15:189197.

[127] Martinez A, Gonzalez F, Capeans C, et al. Dorzolamide effect on ocular blood flow. Invest. Ophthalmol. Vis. Sci. 1999;40:1270-1275.

[128] Josefsson A, Sigurdsson SB, Bang K, et al. Dorzolamide induces vasodilatation in isolated pre-contracted bovine retinal arteries. Exp. Eye Res. 2004;78:215-221.

[129] Torring MS, Holmgaard K, Hessellund A, et al. The vasodilating effect of acetazolamide and dorzolamide involves mechanisms other than carbonic anhydrase inhibition. Invest. Ophthalmol. Vis. Sci. 2009;50:345-351.

[130] Dong Y, Sawada Y, Cui J, et al. Dorzolamide-induced relaxation of isolated rabbit ciliary arteries mediated by inhibition of extracellular calcium influx. Jpn. J. 
Ophthalmol. [Internet]. 2016;60:103-110. Available from:

https://doi.org/10.1007/s10384-015-0423-z.

[131] Moshirfar M, Parker L, Birdsong OC, et al. Use of Rho kinase Inhibitors in Ophthalmology: A Review of the Literature. Med. hypothesis, Discov. Innov. Ophthalmol. J. [Internet]. 2018 [cited 2020 Jul 8];7:101-111. Available from: http://www.ncbi.nlm.nih.gov/pubmed/30386798.

[132] Inagaki N, Gonoi T, Iv JPC, et al. A Family of Sulfonylurea Receptors Determines the Pharmacological Properties of ATP-Sensitive K+ Channels. Neuron [Internet]. 1996;16:1011-1017. Available from:

http://www.sciencedirect.com/science/article/pii/S0896627300801245.

[133] Noma A. ATP-regulated K+ channels in cardiac muscle. Nature. 1983;305:147-148.

[134] Ashford MLJ, Sturgess NC, Trout NJ, et al. Adenosine-5'-triphosphate-sensitive ion channels in neonatal rat cultured central neurones. Pflügers Arch. 1988;412:297-304.

[135] Cook DL, Hales N. Intracellular ATP directly blocks K+ channels in pancreatic Bcells. Nature. 1984;311:271-273.

[136] Chowdhury UR, Bahler CK, Hann CR, et al. ATP-sensitive potassium (KATP) channel activation decreases intraocular pressure in the anterior chamber of the eye. Invest. Ophthalmol. Vis. Sci. [Internet]. 2011;52:6435-6442. Available from: https://www.ncbi.nlm.nih.gov/pubmed/21743021.

[137] Babenko AP, Gonzalez G, Aguilar-Bryan L, et al. Sulfonylurea receptors set the maximal open probability, ATP sensitivity and plasma membrane density of KATP channels. FEBS Lett. [Internet]. 1999;445:131-136. Available from: http://www.sciencedirect.com/science/article/pii/S0014579399001027.

[138] Roy Chowdhury U, Dosa PI, Fautsch MP. ATP sensitive potassium channel openers: A new class of ocular hypotensive agents. Exp. Eye Res. [Internet]. 2017;158:85-93. 
Available from:

http://www.sciencedirect.com/science/article/pii/S0014483516300938.

[139] Atlasz T, Babai N, Reglodi D, et al. Diazoxide is protective in the rat retina against ischemic injury induced by bilateral carotid occlusion and glutamate-induced degeneration. Neurotox. Res. 2007;12:105.

[140] Roy Chowdhury U, Bahler CK, Holman BH, et al. ATP-sensitive potassium (KATP) channel openers diazoxide and nicorandil lower intraocular pressure by activating the Erk1/2 signaling pathway. PLoS One [Internet]. 2017;12:e0179345-e179345. Available from: https://www.ncbi.nlm.nih.gov/pubmed/28594895.

[141] Barbosa-Breda J, Himmelreich U, Ghesquiere B, et al. Clinical Metabolomics and Glaucoma. Ophthalmic Res. 2018;59:1-6.

[142] Burgess LG, Uppal K, Walker DI, et al. Metabolome-Wide Association Study of Primary Open Angle Glaucoma. Invest. Ophthalmol. Vis. Sci. 2015;56:5020-5028.

[143] Mayordomo-Febrer A, Lopez-Murcia M, Morales-Tatay JM, et al. Metabolomics of the aqueous humor in the rat glaucoma model induced by a series of intracamerular sodium hyaluronate injection. Exp. Eye Res. 2015;131:84-92.

[144] Doganay S, Cankaya C, Alkan A. Evaluation of corpus geniculatum laterale and vitreous fluid by magnetic resonance spectroscopy in patients with glaucoma; a preliminary study. Eye (Lond). 2012;26:1044-1051.

[145] Kasi A, Faiq MA, Chan KC. In vivo imaging of structural, metabolic and functional brain changes in glaucoma. Neural Regen. Res. Wolters Kluwer Medknow Publications; 2019. p. 446-449.

[146] Shimazawa M, Ito Y, Inokuchi Y, et al. An Alteration in the Lateral Geniculate Nucleus of Experimental Glaucoma Monkeys: In vivo Positron Emission Tomography Imaging of Glial Activation. Linden R, editor. PLoS One [Internet]. 2012 [cited 2020 
Apr 8];7:e30526. Available from: https://dx.plos.org/10.1371/journal.pone.0030526.

[147] Murai H, Suzuki Y, Kiyosawa M, et al. Cerebral glucose metabolism in the striate cortex positively correlates with fractional anisotropy values of the optic radiation in patients with glaucoma. Clin. Experiment. Ophthalmol. [Internet]. 2015 [cited 2020 Apr 8];43:711-719. Available from: http://doi.wiley.com/10.1111/ceo.12543.

[148] Murphy MC, Conner IP, Teng CY, et al. Retinal Structures and Visual Cortex Activity are Impaired Prior to Clinical Vision Loss in Glaucoma. Sci. Rep. 2016;6.

[149] Sanfilippo PG, Hewitt AW, Hammond CJ, et al. The Heritability of Ocular Traits. Surv. Ophthalmol. Elsevier; 2010. p. 561-583.

[150] Craig JE, Han X, Qassim A, et al. Multitrait analysis of glaucoma identifies new risk loci and enables polygenic prediction of disease susceptibility and progression. Nat. Genet. [Internet]. 2020 [cited 2020 Jul 6];52:160-166. Available from: https://www.nature.com/articles/s41588-019-0556-y.

[151] Mohammadzadeh V, Fatehi N, Yarmohammadi A, et al. Macular imaging with optical coherence tomography in glaucoma. Surv. Ophthalmol. Elsevier USA; 2020.

[152] Bussel II, Wollstein G, Schuman JS. OCT for glaucoma diagnosis, screening and detection of glaucoma progression. Br. J. Ophthalmol. 2014;98 Suppl 2:ii15-9.

[153] Khawaja AP, Chan MPY, Garway-Heath DF, et al. Associations with retinal nerve fiber layer measures in the EPIC-Norfolk Eye Study. Invest. Ophthalmol. Vis. Sci. [Internet]. 2013;54:5028-5034. Available from:

https://pubmed.ncbi.nlm.nih.gov/23821204.

[154] Alasil T, Wang K, Keane PA, et al. Analysis of normal retinal nerve fiber layer thickness by age, sex, and race using spectral domain optical coherence tomography. J. Glaucoma [Internet]. 2013;22:532-541. Available from: https://pubmed.ncbi.nlm.nih.gov/22549477. 
[155] Chen C-Y, Huang EJ-C, Kuo C-N, et al. The relationship between age, axial length and retinal nerve fiber layer thickness in the normal elderly population in Taiwan: The Chiayi eye study in Taiwan. PLoS One [Internet]. 2018;13:e0194116. Available from: https://doi.org/10.1371/journal.pone.0194116.

[156] Harwerth RS, Vilupuru AS, Rangaswamy N V, et al. The relationship between nerve fiber layer and perimetry measurements. Invest. Ophthalmol. Vis. Sci. 2007;48:763 773.

[157] Shamsher E, M. Davis B, Yap T, et al. Neuroprotection in glaucoma: old concepts, new ideas. Expert Rev. Ophthalmol. 2019.

[158] *Cordeiro MF, Guo L, Luong V, et al. Real-time imaging of single nerve cell apoptosis in retinal neurodegeneration. Proc. Natl. Acad. Sci. U. S. A. [Internet]. 2004/08/30. 2004;101:13352-13356. Available from:

https://pubmed.ncbi.nlm.nih.gov/15340151.

*Proof-of-concept study. First study to visualise neuronal cell apoptosis in vivo. Details the safety and tolerablitiy of flourescently labelled annexin 5 (ANX776). DARC count found to be higher in glaucoma patients than controls and appears to be predictive of progressive disease.

[159] Yap TE, Shamsher E, Guo L, et al. Ophthalmic Research Lecture 2018: DARC as a Potential Surrogate Marker. Ophthalmic Res. [Internet]. 2019/08/09. 2020;63:1-7. Available from: https://pubmed.ncbi.nlm.nih.gov/31401622.

[160] Cordeiro MF, Normando EM, Cardoso MJ, et al. Real-time imaging of single neuronal cell apoptosis in patients with glaucoma. Brain [Internet]. 2017 [cited 2019 Aug 14];140:1757-1767. Available from: https://academic.oup.com/brain/article/140/6/1757/3755374.

[161] Barnett EM, Zhang X, Maxwell D, et al. Single-cell imaging of retinal ganglion cell apoptosis with a cell-penetrating, activatable peptide probe in an in vivo glaucoma 
model. Proc. Natl. Acad. Sci. U. S. A. 2009;106:9391-9396.

[162] Qiu X, Johnson JR, Wilson BS, et al. Single-cell resolution imaging of retinal ganglion cell apoptosis in vivo using a cell-penetrating caspase-activatable peptide probe. PLoS One. 2014;9:e88855.

[163] Rossi EA, Granger CE, Sharma R, et al. Imaging individual neurons in the retinal ganglion cell layer of the living eye. Proc. Natl. Acad. Sci. U. S. A. [Internet]. 2017/01/03. 2017;114:586-591. Available from:

https://pubmed.ncbi.nlm.nih.gov/28049835. 


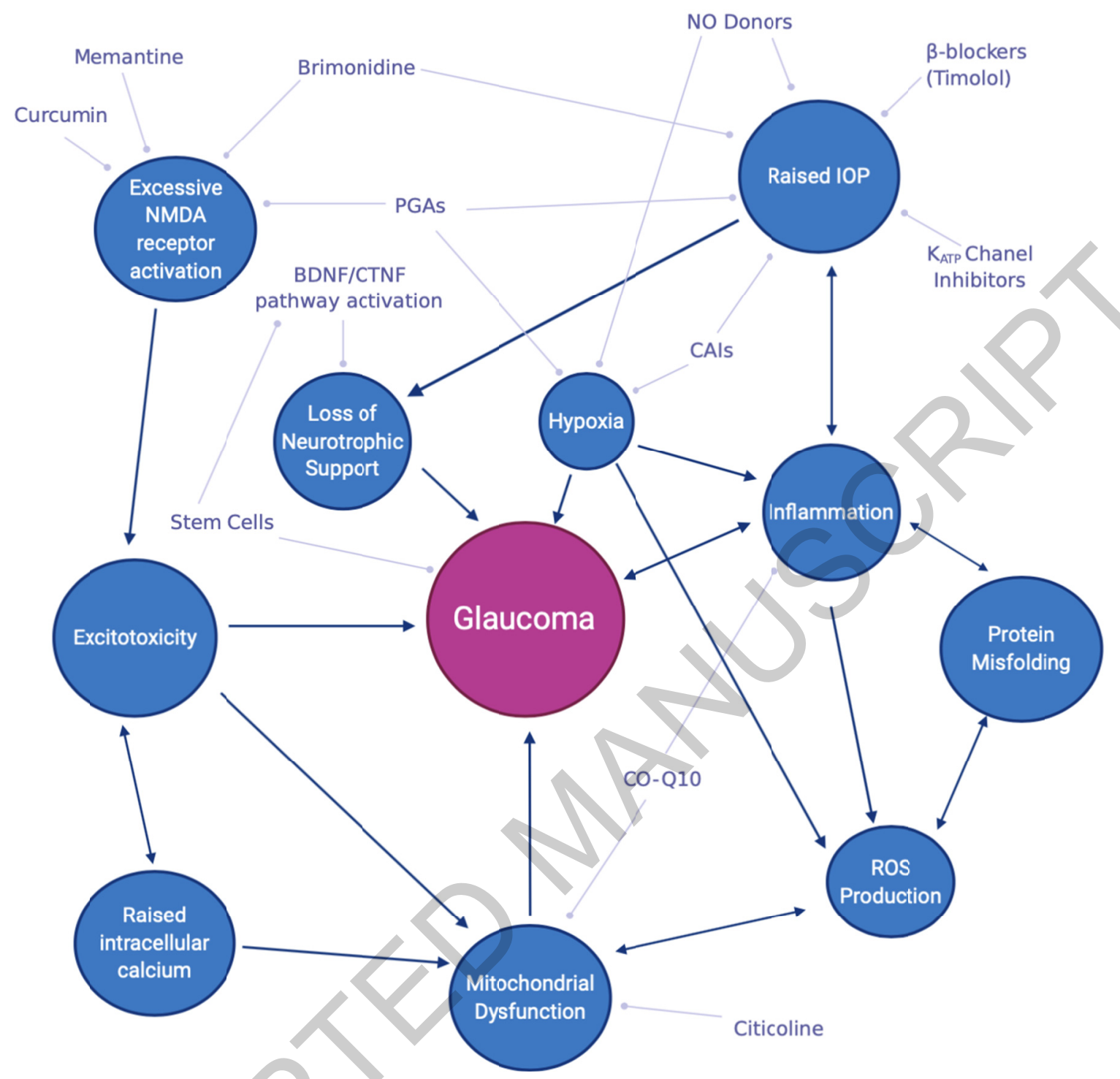

(FIGURE 1: Network of Glaucomatous Pathways - A diagram summarising the current understanding of the multiple pathways interacting in the aetiology of glaucoma, as well as the therapies discussed in this review article. Abbreviations: Co-Q10, Coenzyme Q10; CAIs, carbonic anhydrase inhibitors; PGAs, prostaglandin analogues; NO donors, nitric oxide donors.) 


\begin{tabular}{|c|c|c|c|}
\hline Target & Agent & Mechanism of Action & Recent experimental Evidence \\
\hline \multirow{3}{*}{ 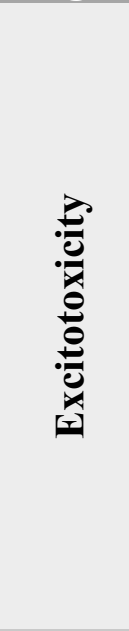 } & $\begin{array}{l}\text { Memantine [20, } \\
\text { 24-26] }\end{array}$ & $\begin{array}{l}\text { Non-competitive NMDA } \\
\text { receptor antagonist. }\end{array}$ & $\begin{array}{l}\text { Extensive pre-clinical evidence } \\
\text { however no efficacy shown in } \\
\text { large randomised controlled trials } \\
\text { in glaucoma. }\end{array}$ \\
\hline & $\begin{array}{l}\text { Brimonidine [27- } \\
30]\end{array}$ & $\begin{array}{l}\alpha 2 \text { adrenergic receptor } \\
\text { agonist. }\end{array}$ & $\begin{array}{l}\text { LoGTS study found brimonidine } \\
\text { to reduce progression of visual } \\
\text { field loss more than timolol, a } \\
\text { comparable IOP-lowering drug. }\end{array}$ \\
\hline & $\begin{array}{l}\text { Curcumin [31- } \\
34,36]\end{array}$ & $\begin{array}{l}\text { Antioxidative and anti- } \\
\text { inflammatory properties. } \\
\text { Activates CaPKII and } \\
\text { protects against } \\
\text { mitochondrial dysfunction. }\end{array}$ & $\begin{array}{l}\text { Application of curcumin-loaded } \\
\text { nanoparticles demonstrate RGC } \\
\text { protection in rodent models of } \\
\text { optic nerve disease, OHT and } \\
\text { pONT, compared to controls. }\end{array}$ \\
\hline \multirow{2}{*}{ 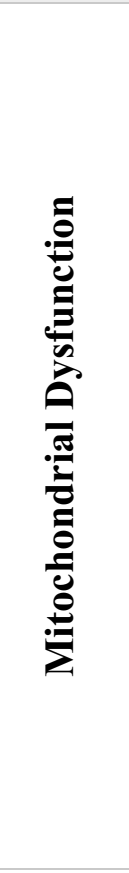 } & $\begin{array}{l}\text { Coenzyme-Q10 } \\
{[83-85,48]}\end{array}$ & $\begin{array}{l}\text { Mitochondrial-targeting } \\
\text { antioxidant. }\end{array}$ & $\begin{array}{l}\text { Clinical trials show improvement } \\
\text { in inner retinal function (PERG) } \\
\text { and VEPs. Results of double- } \\
\text { masked RCT evaluating efficacy } \\
\text { of Co-Q10, vitamin E, PGA } \\
\text { combination awaited } \\
\text { (NCT03611530). }\end{array}$ \\
\hline & $\begin{array}{l}\text { Citicoline [ } 49, \\
105-107]\end{array}$ & $\begin{array}{l}\text { Endogenous } \\
\text { mononucleotide with } \\
\text { neuroprotective properties. } \\
\text { Maintains cardiolipin and } \\
\text { sphingomyelin } \\
\text { concentrations in } \\
\text { mitochondria, restoring } \\
\text { phosphatidylcholine levels } \\
\text { and increasing } \\
\text { concentration of Ach, NA } \\
\text { and 5-HT. }\end{array}$ & $\begin{array}{l}\text { Clinical trials show improvement } \\
\text { in inner retinal function (PERG) } \\
\text { and VEPs. Results of double- } \\
\text { masked, placebo-control trial of } \\
\text { eyedrops awaited } \\
\text { (NCT04020705). }\end{array}$ \\
\hline \multirow{3}{*}{ 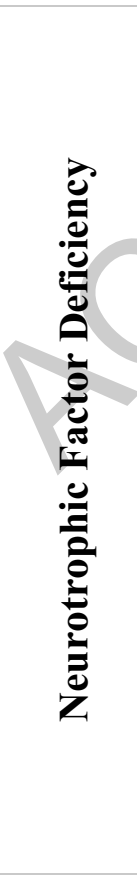 } & $\begin{array}{l}\text { BDNF \& N-tert- } \\
\text { butyl-(2- } \\
\text { sulfophenyal)- } \\
\text { nitrone [71] }\end{array}$ & $\begin{array}{l}\text { Combined neurotrophic } \\
\text { factor and free radical } \\
\text { scavenger. BDNF } \\
\text { enhances neuronal cell } \\
\text { function and promotes } \\
\text { axon regeneration. }\end{array}$ & $\begin{array}{l}\text { Intravitreal injection demonstrates } \\
\text { increased RGC survival in rats } \\
\text { with raised IOP, however topical } \\
\text { application yields poor } \\
\text { pharmacokinetics. }\end{array}$ \\
\hline & $\begin{array}{l}\text { 7,8- } \\
\text { dihydroxyflavone } \\
(7,8-\mathrm{DHF})[76, \\
77]\end{array}$ & $\begin{array}{l}\text { TrkB agonist. Upregulates } \\
\text { downstream AKT and } \\
\text { MAPK/ERK cell survival } \\
\text { signalling pathways. }\end{array}$ & $\begin{array}{l}\text { In vitro studies demonstrate dose- } \\
\text { dependent activation of TrkB } \\
\text { receptors and improved survival } \\
\text { of chemically stressed cells. }\end{array}$ \\
\hline & $\begin{array}{l}\text { CNTF (NT-501 } \\
\text { device) }[81,82, \\
85]\end{array}$ & $\begin{array}{l}\text { Neurotrophic factor. } \\
\text { Upregulates Stat } 3 \text { and } \\
\text { MAPK cell survival } \\
\text { pathways. }\end{array}$ & $\begin{array}{l}\text { Virally mediated increase in } \\
\text { CNTF expression shown to be } \\
\text { neuroprotective in rodent } \\
\text { glaucoma models. Results of } \\
\text { phase II randomised, sham- } \\
\text { controlled, masked trial of } \\
\text { encapsulated cell therapy awaited } \\
\text { (NCT02862938). }\end{array}$ \\
\hline
\end{tabular}


(TABLE 1: Table summarizing key candidate glaucoma therapies with IOP-independent modes of action, as well as their mechanism of action and most recent experimental evidence surrounding their use. Abbreviations: NMDA, $N$-methyl-D-aspartic acid; RCT, Randomized control trial; OHT, Ocular hypertension; IOP, Intra-ocular pressure; pONT, Partial optic nerve transection; PERG, Pattern electroretinogram; VEP, Visual evoked potential; Ach, Acetylcholine; NA, Nor-Adrenaline; 5-HT, Serotonin.). 